https://www.journal-imab-bg.org

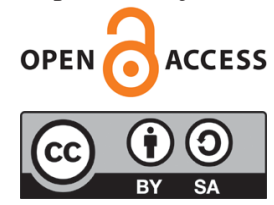

Original article

\title{
DIETARY GUIDELINES FOR PROTECTION OF THE OCCUPATIONAL HEALTH OF WORKERS IN FORESTRY
}

\author{
Irena Y. Stoilova, Vanya A. Birdanova \\ Department of Hygiene Medical Ecology, Occupational Diseases and Disaster \\ Medicine, Faculty of Public Health, Medical University of Pleven, Bulgaria.
}

\begin{abstract}
Introduction: Healthy and safe working conditions in the Bulgarian forest economy are associated with a lower incidence of labor abuses and occupational diseases among forest workers. Strategic management in this area includes actions to improve the working environment, part of which is the organization of pre-occupational nutrition.

Purpose of the study is to support the occupational health of forest workers with specific dietary guidelines.

Methods: The object of the study is 105 workers employed in the forestry of Northern Bulgaria. A documentary method was used - a study of the medical documentation from preventive examinations conducted in the period from 2015 to 2019 . The results were analyzed with statistical software SPSS v.20.

Results: Dietary recommendations in forestry aim to reduce the occupational health risk from contact with biological hazards, cold and hot microclimate, noise, dust and forced working posture. Dietary guidelines include adequate hydration, recommended eating frequency with a mandatory snacks, consumption of animal foods, fruits and vegetables, which increase the intake of essential amino acids, dietary fiber, vitamins (A, C, B $, B_{2}, B_{6}$ ), calcium, magnesium and trace elements, limiting the intake of saturated fatty acids and sodium, provision of dining facilities, clean food and clean drinking water. The training of forest workers to regulate energy intake is also being discussed.

Conclusion: The implementation of dietary recommendations based on leading occupational hazards in forestry will help to protect occupational health and safety at work.
\end{abstract}

Keywords: dietary guidelines, forestry, occupational health, nutrition,

\section{INTRODUCTION}

The forest territories in the Republic of Bulgaria occupy 4,222,874 hectares (ha) or approximately $38 \%$ of the country's area, and in recent years the total wood stock is constantly growing by $4 \mathrm{~m}^{3} /$ ha per year [1]. Although the forest sector forms a relatively small share of the country's gross domestic product, forestry and forest industry as traditional Bulgarian livelihoods are particularly important for rural development and the creation of new jobs [2]. As the forest sector is one of the industries with the highest risk of accidents, prevention programs to maintain a healthy and safe working environment should not be underestimated [3].

Workers in modern forestry are exposed to a number of occupational hazards such as extreme hot or cold microclimate, noise, vibration, wood dust, exhaust fumes (especially carbon monoxide, carbon dioxide, sulfur oxides, nitrogen oxides), fixed or constrained body positions, contact with wild animals, insects and reptiles, dangerous activity as work with chainsaws, excessive physical load, electromagnetic radiation, insufficient lighting at the workplace $[4,5]$.

Efforts to maintain physical and mental performance in the forest work environment require continuous development and improvement of the system of preventive measures. Precautionary occupational nutrition, aimed at reducing health risks from the effects of occupational hazards in this sector, is part of modern programs for the prevention and protection of health and safety. Nutrition studies in different occupations showed specific dietary intake characteristics and differences in diet related to working conditions and the organization of the work environment, which would be useful to design the dietary guidelines for the protection of occupational health at the workplace $[6,7]$.

\section{OBJECTIVES}

The objective of this ongoing study is to support the occupational health of forest workers with specific dietary guidelines.

\section{MATERIALS AND METHODS}

The object of the study is 105 employed active workers (average age $-44.5 \pm 6.1, \mathrm{n}=105$ ) in forestry in Northern Bulgaria. Clinical, laboratory and statistical diagnostic methods have been used [8]. Sources of health information are medical documentation for conducted preventive examinations and data on general and occupational morbidity, as well as occupational injuries for the period 20152019. The data were processed with statistical software IBM SPSS Statistics v.24. for Windows. The results regarding dietary recommendations for forest workers were analyzed using age, gender, work experience and occupa- 
tional hazards at the workplace as independent variables. Gender, age, work experience in years and risk factors at the workplace were used as independent variables in the analysis of the results on dietary recommendations. Dietary reference intakes (DRIs) issued by the Bulgarian Ministry of Health were also used as a reference [9]. A significance level of $\alpha=0.05$ using t-tests was considered statistically significant.

\section{RESULTS}

In this study, about two-thirds of the respondents were men (105 workers) with an average work experience of $14.5 \% \pm 4.1$ years $(n=105)$. The shortest work experience in forestry (less than 3 years) was reported only by $11 \%$ of respondents, the longest work expåriånce (more than 10 years) $-48 \%$, while the percentage of those with the period of employment from 3-10 years was 40,7\%. The relative share of the youngest workers in the survey aged 18 to 30 was $14 \%$. One third $(33,3 \%)$ of workers in the study group was aged 41-50 y, 23,3\% were aged 31-40 y, 26\% were aged 51-60 y, and only 3,4\% of employees were aged over 60 years. The distribution of forestry workers în the workplace was as follows: wood cutters $-24,6 \%$, mechanics (tractor driver) - 24\%, garden workers $-23,3 \%$, forest rangers $-12,7 \%$, foresters $-10,7 \%$ and office workers $4,7 \%$.

The distribution of energy intake of forest workers was made according to their daily energy expenditure determined on the basis of gender, age and level of physical activity in the workplace.Òhe results showed significant gender differences in the distribution of daily energy expenditure $(\mathrm{p}<0.05)$. For men, workplace with high (foresters, warden, woodcutter) and moderate energy expenditure (crane operators, car/truck drivers, etc.) predominate, while for women, the leading workplaces were with moderate and low energy expenditure. The average daily energy needs of $75 \%$ of men were high, respectively $2939 \mathrm{kcal} / \mathrm{day}$, and $23 \%$ of them were moderate - $2612 \mathrm{kcal} /$ day). In percentage, $87 \%$ of women were moderate average energy needs $2083 \mathrm{kcal} /$ day, and $13 \%$ of them were low average energy needs - $1823 \mathrm{kcal} /$ day. In this study, $75 \%$ of forest men workers carried out activities related to heavy physical labor [Figure 1 and Figure 2].

Fig. 1. Distribution of energy expenditure of men forest workers

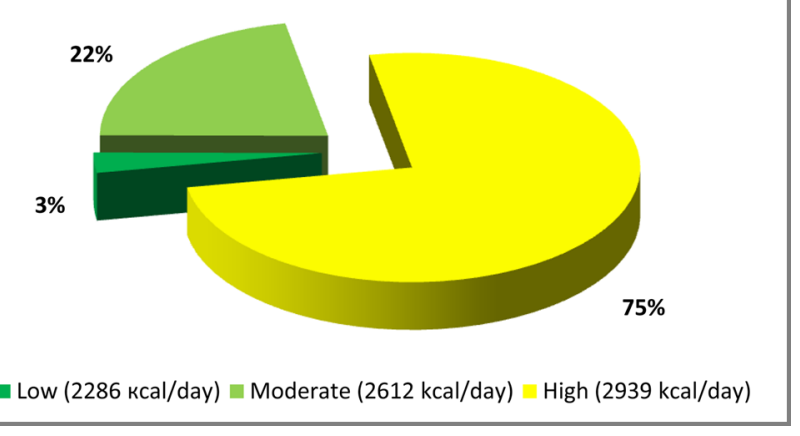

Fig. 2. Distribution of energy expenditure of women forest workers

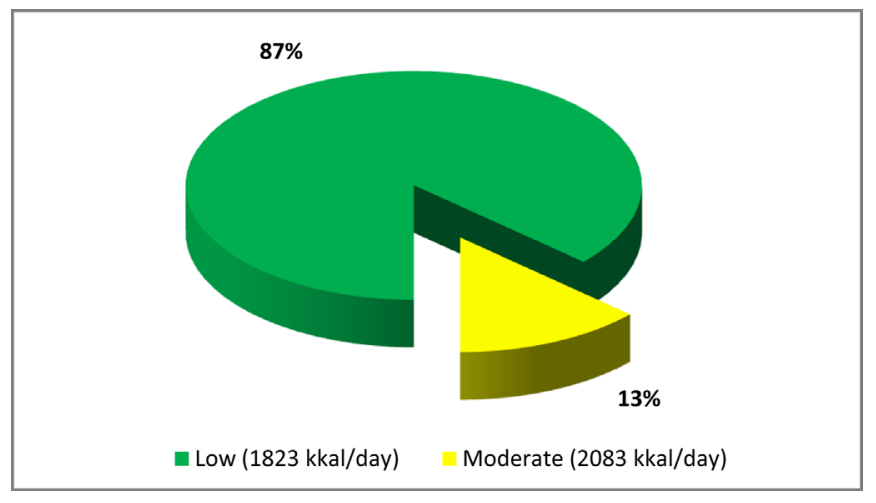

As shown in Figure 3. dietary recommendations for forest workers should be aimed at reducing health risk and nutritional protection against contact with biological agents, overexertion of certain muscle groups from unfavorable working positions (forced working posture) and against the leading physical factors - extreme cold and hot microclimate, noise, as well as organic dust of plant origin.

Fig. 3 Forest workers exposed to risk factors (n)

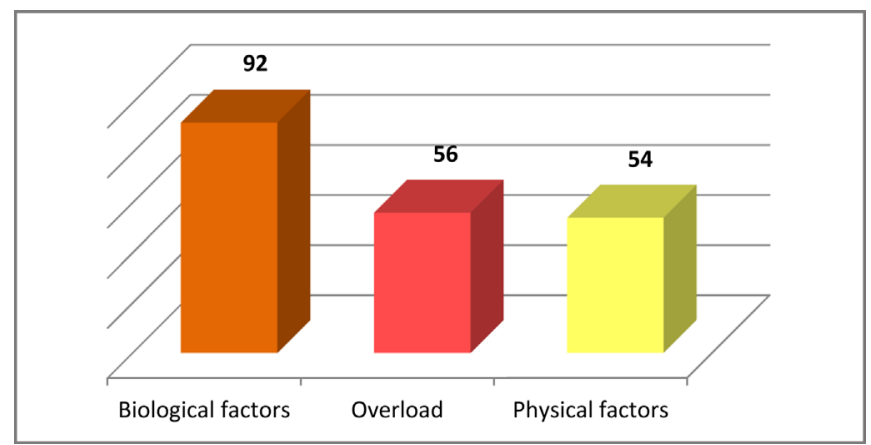

\section{DISCUSSION}

Most harvesting, handling and forest protection activity demand great physical exertion, so to provide the caloric and nutritional density food are important for proper organized occupational nutrition of forestry workers. The results of modern studies of real nutrition in forestry showed that in this occupational group, an unhealthy eating pattern is established. Forestry workers consumed a fat-rich diet, a high intake of trans and saturated fatty acids, salt, added sugar, consumption of alcohol daily or sporadically. Furthermore, the daily intakes of calcium, potassium, dietary fibres and some vitamins $-\mathrm{A}, \mathrm{B}_{1}, \mathrm{C}$ were under dietary reference values DRVs [10].

The workplace is a suitable place to improve dietary behaviors and intake because workers spend a long time at their workplace. Tanaka et al. found significant differences in dietary intake and eating behavior based on the professional status of participants. In this study, forestry of Bulgaria belongs to male-dominated industries or occupations (> 70\% male workforce). Promoting a healthy diet and healthy eating behavior among forestry men in their 
workplace is important because they reported inadequate knowledge about food-based dietary guidelines [11].

Dietary recommendations guide forest workers to choose certain foods and nutrients that reduce the risk of disorders in the body caused by the occupational hazards to which they are exposed. The diet is varied, balanced, corresponding to the physiological needs of energy and nutrients of forest workers to avoid the risk of nutritional deficiencies that reduce the body's immune defenses. The scientific criteria for developing specific nutritional recommendations are based on the nature of occupational hazards (biological, physical, overexertion) and the role of certain nutrients and foods in reducing its impact, as well as in suppressing major manifestations and preventing complications from occupational diseases.

\section{Biological hazards}

Over $80 \%$ of forest workers are exposed to biological occupational risk due to sporadic or continuous contact with many infectious agents causing zoonotic diseases [12]. Among forestry workers in Europe, a higher frequency of Lyme borreliosis, tularemia and leptospirosis are found compared with the common population. In Europe, these three zoonotic diseases are considered emerging or reemerging infection risks [13]. The definition of occupational risk and diagnosing them as work-related diseases is difficult, and these zoonoses are under-reported as occupational diseases. Precautions zoonoses in forest environments are designed to avoid direct contact with contaminated water and soil, animals, wild wasps and other insects. The most effective preventive measure that significantly reduces the risk of infection is wearing personal protective clothing. The specific importance of nutrition is linked to the prevention of oral contamination with infectious agents. Particular attention is paid to the picking and consumption of forest mushrooms and berries such as raspberries, blackberries, etc., as well as adequate heat treatment of game meat before feeding. Forestry workers should not drink untreated water. Laboratory studies in animal models and human observational studies have shown an association between certain zoonoses and the micronutrient status of the host $[14,15]$. The potential role of the micronutrients iron, calcium and magnesium in Leptospira infection is discussed. Limited data in this area do not allow specific recommendations to be made for micronutrient intake or supplementation in at-risk populations.

\section{Overload}

Most activities performed by forest workers require high physical activity and high energy expenditure, which is important in determining the daily caloric intake of food. Intensive mechanization in forestry in recent years has replaced much of the work that is usually done with great muscular effort. Workers are gradually becoming more sedentary, which reduces the average daily energy needs from high to moderate, increases the risk of consuming more energy than necessary, which leads to the accumulation of excess fat and the risk of widespread overweight and obesity $[16,17]$. In this study, $75 \%$ of workers perform heavy non-mechanized or semi-mechanized work associated with static and dynamic loading of large muscle groups (back, limbs, lumbar region), which determines their higher energy costs. Almost all women $(87 \%)$ and about $1 / 4$ of men perform activities with moderate physical activity. Balancing energy intake with food, in accordance with the daily energy expenditure of different professions in forestry, maintains not only normal body weight but also active muscle mass, which is important due to the high proportion of respondents exposed to overexertion. Energy intake is met by the calculated amounts of macronutrients - proteins, fats and carbohydrates, in accordance with their recommended energy ranges. Forest workers need to be informed and trained to regulate their energy intake in order to maintain a healthy weight and maintain their physical capacity.

In addition, about $1 / 3$ of the participants in this study are over the age of 50. Dietary intake of biologically active protein and branched-chain amino acids - leucine, isoleucine and valine are essential to prevent age-related sarcopenia. Therefore, in order to maintain skeletal muscle mass in forest workers performing heavy physical exertion, proteins and amino acids of high biological value from meat and milk is recommended [18]. The beneficial effects of energy-adjusted dietary intake of the amino acids leucine and isoleucine on skeletal body mass are greater in non-obese individuals $[19,20]$.

\section{Physical hazards and nutrition}

Hot or cold microclimate, noise and vibration are common physical hazards in forestry work. Mîst of the participants in this study were exposed to physical risk factors. Exposure to physical hazards varies greatly depending on the type of work and the equipment used. Statistically significant relationships are described between the better diet quality and the better health status of the participants with different exposure to physical factors [21]. High-quality and balanced diets support basic cellular processes related to the influence of physical factors on stress reactions, immune protection, endothelial dysfunction, neuronal and mental status. A protective diet for workers exposed to noise, vibration and high temperatures above $30^{\circ} \mathrm{C}$ is rich in animal proteins (essential amino acids), polyunsaturated fatty acids, biologically active substances (vitamins and antioxidants), cocoa and caffeine-containing foods and beverages [22]. The following foods are preferentially included in the menu of the forestry workers - egg, liver, cottage cheese, yogurt, chicken, beef, fish, nuts, wholemeal bread, oatmeal and other whole grain snacks. Dietary intake of fatty meats, salty and smoked foods, spicy sauces and confectionery, which are rich in saturated fatty acids, cholesterol, added sugar and salt, is limited. Some vitamins - A, B 12 and folic acid, have a considerable protective effect as antioxidants to reduce occupational hearing loss. Ji Eun Choi and et. revealed that higher dietary intakes of seeds, nuts and fresh fruits were positively associated with better hearing [23, 24]. Findings regarding the protective effect of vitamins $\mathrm{C}, \mathrm{D}, \mathrm{B}_{1}, \mathrm{~B}_{2}, \mathrm{~B}_{6}$ are inconsistent, but studies highlight their important role in protective occupational nutrition for workers exposed to 
physical hazards. For the prevention of occupational diseases in forestry, it is necessary that the dietary intake of the above vitamins met their recommendations [Table 1], which means greater and more frequent consumption of dietary antioxidants or anti-inflammatory foods, including fresh fruits and vegetables.

Table 1. Dietary reference values (DRVs) of some important vitamins for forest workers

\begin{tabular}{|c|c|c|c|c|c|c|c|c|}
\hline $\begin{array}{l}\text { Nutrients } \\
\text { (Units) }\end{array}$ & $\begin{array}{c}\mathrm{A} \\
(\mu \mathrm{g} \mathrm{RE})\end{array}$ & $\begin{array}{c}\mathrm{D} \\
(\mathrm{mg})\end{array}$ & $\begin{array}{c}\mathrm{B}_{1} \\
(\mathrm{mg})\end{array}$ & $\begin{array}{c}\mathrm{B}_{2} \\
(\mathrm{mg})\end{array}$ & $\begin{array}{c}\mathrm{B}_{6} \\
(\mathrm{mg})\end{array}$ & $\begin{array}{l}\mathrm{C}^{*} \\
(\mathrm{mg})\end{array}$ & $\begin{array}{c}\text { Folate } \\
(\mu \mathrm{g} D F E)\end{array}$ & $\begin{array}{l}\mathrm{B}_{12} \\
(\mu \mathrm{g})\end{array}$ \\
\hline DRVs** & 800 & 15 & 1,2 & 1,3 & 1,3 & 145 & 330 & 4 \\
\hline
\end{tabular}

\section{Adequate hydration}

Adequate fluid and electrolyte intake during the summer is especially important to prevent injuries to workers in agriculture, forestry or fishing due to high temperatures. The increase in the maximum temperature by $1{ }^{\circ} \mathrm{C}$ was associated with a $1.4 \%(\mathrm{RR}=1.014,95 \%$ CIs $1.012-1.017)$ significant increase in daily work-related injuries in middle-aged men employed in the manufacturing sector [25]. The most important is to supply the liquid in good quality. Mineral water, fruit juices, fresh juices and kefir are recommended. The temperature of the drinks is in the range between $8-12^{\circ} \mathrm{C}$. Adequate hydration keeps working capacity and ability to concentate, maintains the volume, resilience and differential attention ability, and significantly reduces the risk of injury in the second part of workday and at the end of the workweek [26]. During heavy physical work in the summer (high temperature), forestry workers need approximately 1 liter of fluids per hour. Consumption of alcohol should be strictly forbidden. Alcohol increases the body's dehydration.

\section{Regular breakfast}

Regarding irregular eating habits for this occupational category of workers, it is important to note the contribution of the mandatory breakfast to micronutrient intake and especially calcium intake if breakfast contains dairy products. A regular breakfast will provide an average of 1/4 dietary fiber and $1 / 3$ of calcium, folate and riboflavin from the daily reference values. Eating at least three main meals a day with mandatory breakfast will improve compliance with nutritional recommendations of dietary fiber, calcium, folate and riboflavin in forestry workers [27, 28].

\section{Nutrition in the workplace}

Nutrition in forestry depends on the level of sanitation and comfort on the campus. The infrastructure of the kitchen is the most critical place in the forest camp. The personnel in the kitchen must have the appropriate qualification and health licenses and be regularly monitored. The HACCP system in the camp kitchen must be applied to effectively manage food safety [29]. Adequate and balanced nutrition incorporate a greater variety of daily and weekly menus. However, most forest workers live in their homes and travel to their jobs. In this case, forestry workers follow the family diet and most often used catering facilities in the nearest locality, mainly for lunch. If be inconvenient for workers to return to the forest camp or visit the nearest catering establishment for lunch, safely packaged lunches must be provided for them or the same to be delivered to their workplace.

\section{CONCLUSION}

In conclusion, the use of the pharmacological action of nutrition through effective dietary recommendations is directed not only to the preservation of health and safety at work but also to the prevention of major chronic noncommunicable diseases, such as circulatory diseases, type 2 diabetes, etc., whose frequency in the studied professional group does not differ from that of the modern Bulgarian population.

\section{REFERENCES:}

1. National report on the state and protection of the environment in the Republic of Bulgaria. MOEW, EEA Sofia. 2019. [in Bulgarian] [Internet]

2. Strategic Plan for the Development of the Forest Sector 2014-2023. Ministry of Agriculture and Food, Sofia. [in Bulgarian] [Internet]

3. Perron D. [Accident at work and occupational diseases for the foresters.] [in French] Sante Publique. 2019 May 13;S1(HS):43-49. [PubMed]

4. Pecyna A, Buczaj A, Lachowski S, Choina P, Gozdziewska M, Galinska
EM. Occupational hazards in opinions of forestry employees in Poland. Ann Agric Environ Med. 2019 Jun 17;26(2): 242-48. [PubMed]

5. Stoilova I, Dekov D, Birdanova V. [Production factors and health impairments in forestry workers.] Health Policy and Management. 2019; 19(2):206-10. [in Bulgarian]

6. Tanaka R, Tsuji M, Senju A, Kusuhara K, Kawamoto T; Japan Environment and Children's Study Group. Dietary Differences in Male Workers among Smaller Occupational
Groups within Large Occupational Categories: Findings from the Japan Environment and Children's Study (JECS). Int J Environ Res Public Health. 2018 May; 15(5):961. [PubMed]

7. Tsiga E, Panagopoulou E, Niakas D. Health promotion across occupational groups: one size does not fit all. Occup Med. 2015 Oct;65(7):552-7. [Pubmed]

8. Charakchiev D. (editor) [Laboratory diagnostics of occupational diseases and ecopathology.] Bulgarian 
Publishing House Ltd., Sofia. 2006. pp.221-25. [in Bulgarian]

9. Ministry of Health. [Ordinance No.1 on physiological norms for the nutrition of the population.] [in Bulgarian] Sofia. January 22, 2018. [Internet]

10.Tanaka R, Tsuji M, Asakura K, Senju A, Shibata E, Kusuhara K, et al.Variation in Men's Dietary Intake Between Occupations, Based on Data From the Japan Environment and Children's Study. Am J Mens Health. 2018 Sep;12(5):1621-34. [PubMed]

11. Hirai VHG, Ribeiro BMDSS, Novaes TB, Martins JT, Teston EF. Prevalence of dyslipidemia among employees of a pulp and paper company. Rev Bras Med Trab. 2020 Jan 9;17(1):54-60. [PubMed]

12. Jánová E. Emerging and threatening vector-borne zoonoses in the world and in Europe: a brief update. Pathog Glob Health. 2019 Mar; 113(2):49-57. [PubMed]

13. Richard S, Oppliger A. Zoonotic occupational diseases in forestry workers - Lyme borreliosis, tularemia and leptospirosis in Europe. Ann Agric Environ Med. 2015; 22(1):43-50. [PubMed]

14. Irak K, Çelik BA, Karakoç Z, Çelik ÖY, Mert H, Mert N, et al. Oxidant/Antioxidant Status, PON1 and ARES Activities, Trace Element Levels, and Histological Alterations in Sheep with Cystic Echinococcosis. Iran J Parasitol. 2018; 13(3): 448-56. [PubMed]

15. Herman HS, Mehta S, Cárdenas WB, Stewart-Ibarra AM, Finkelstein JL. Micronutrients and Leptospirosis: A Review of the Current Evidence.
PLoS Negl Trop Dis. 2016 Jul 7; 10(7):e0004652. [PubMed]

16.Habip Eroglu, Rahmi Yilmaz \& Yildirim Kayacan. A Study on Determining the Physical Workload of the Forest Harvesting and Nursery-Afforestation Workers. The Anthropologist. 2015; 21(1-2):168-81. [Crossref]

17. Habip Eroglu, Yildirim Kayacan \& Rahmi Yilmaz Effects of Work Types and Workload on Certain Anthropometric Parameters in Forestry Workers. The Anthropologist. 2015 Jun;20(3):515-22. [Crossref]

18. So E, Joung H. Effect of Dairy Protein Intake on Muscle Mass among Korean Adults: A Prospective Cohort Study. Nutrients. 2020 Aug 21;12(9): 2537. [PubMed]

19. Chae M, Park HS, Park K. Estimation of Dietary Amino Acid Intake and Independent Correlates of Skeletal Muscle Mass Index among Korean Adults. Nutrients. 2020 Apr 10;12(4): 1043. [PubMed]

20. Chae M, Park HS, Park K. Association between dietary branchedchain amino acid intake and skeletal muscle mass index among Korean adults: Interaction with obesity. Nutr Res Pract. 2021 Apr;15(2):203-12. [PubMed]

21. Spankovich C, Le Prell CG. Associations between dietary quality, noise, and hearing: data from the $\mathrm{Na}-$ tional Health and Nutrition Examination Survey, 1999-2002. Int J Audiol. 2014 Nov;53(11):796-809. [PubMed]

22.Lee SY, Jung G, Jang MJ, Suh MW, Lee JH, Oh SH et al. Association of Coffee Consumption with Hearing and Tinnitus Based on a National
Population-Based Survey. Nutrients. 2018 Oct 4;10(10):1429. [PubMed]

23.Abbasi M, Pourrajab B, Tokhi MO. Protective effects of vitamins/ antioxidants on occupational noise-induced hearing loss: A systematic review. J Occup Health. 2021 Jan;63(1): e12217. [PubMed]

24. Choi JE, Ahn J, Moon IJ. Associations between Age-Related Hearing Loss and DietaryAssessment Using Data from Korean National Health and Nutrition Examination Survey. Nutrients. 2021;13(4):1230. [PubMed]

25. Sheng R, Li C, Wang Q, Yang L, Bao J, Wang $\mathrm{K}$ et al. Does hot weather affect work-related injury? A case-crossover study in Guangzhou, China. Int J Hyg Environ Health. 2018 Apr;221(3):423-28. [PubMed]

26. Flouris AD, Dinas PC, Ioannou LG, Nybo L, Havenith G, Kenny GP et al.Workers' health and productivity under occupational heat strain: a systematic review and meta-analysis. Lancet Planet Health. 2018 Dec; 2(12):521-31. [PubMed]

27. Uzhova I, Mullally D, Peñalvo JL, Gibney ER. Regularity of Breakfast Consumption and Diet: Insights from National Adult Nutrition Survey. Nutrients. 2018 Oct 26;10(11): 1578. [PubMed]

28. Food based dietary guidelines for adults in Bulgaria. Ministry of Health, NCPHP, Sofia. 2006. [Internet]

29. Wallace CA. HACCP-based food safety management systems: great in theory but can we really make them work in practice? Perspect Public Health. 2014 Jul;134(4):188-90. [PubMed]

Please cite this article as: Stoilova IY, Birdanova VA. Dietary guidelines for protection of the occupational health of workers in forestry. J of IMAB. 2021 Oct-Dec;27(4):4103-4107. DOI: https://doi.org/10.5272/jimab.2021274.4103

Received: 31/05/2021; Published online: 18/11/2021

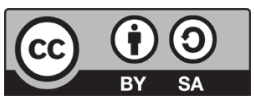

\section{Address for correspondence}

Irena Yordanova Stoilova

Department of hygiene, medical ecology, occupational diseases and disaster medicine, Medical University-Pleven,

1, Sv. Kliment Ohridski Str., Pleven, Bulgaria

E-mail: irena.stoilova444@abv.bg, 